\title{
Steroide Cevaplı Rekürren Ani İşitme Kaybı
}

\author{
Recurrent Sudden Hearing Loss Responsive to Steroid
}

\section{Gökçe ŞİMŞEK ${ }^{1}$, Hatice GÜZELKÜÇÜK ${ }^{1}$, Rahmi KILIÇ ${ }^{1}$}

${ }^{1}$ Kırıkkale Üniversitesi Tıp Fakültesi, Kulak Burun Boğaz Hastalıkları Anabilim Dalı, KIRIKKALE

\begin{abstract}
ÖZET
Ani işitme kaybı, etyolojisinin tam aydınlatılamadığı ve tedavide tam bir standardizasyonun olmadığı sık görülen klinik bir durumdur. Rekürren ani işitme kaybı ise oldukça nadir görülür. Rekürren hastalığın düşük ve yüksek frekansları tutan klinik tipleri bulunmaktadır. Düşük frekanslarda sensörinöral kayıpla karakterize idiyopatik ani işitme kaybı etyolojisi bilinmeyen diğerlerinden, yüksek frekanslarda işitme eşiklerinin korunması ve vertigo, bulantı, kusma gibi vejetatif bulguların olmamasıyla ayrılır. Bu yazıda birkaç ay ara ile 4 kez unilateral ani işitme kaybı geçiren olgu sunuldu. Birkaç gündür devam eden sağ kulakta çınlama, uğultu ve işitme kaybı yakınması ile 50 yaşında erkek hasta kliniğimize başvurdu. Otoskopik muayenesi doğal olan hastanın düşük frekanslarda $55 \mathrm{~dB}$ sensörinöral işitme kaybı mevcuttu. Hospitalize edilen hastaya intravenöz steroid tedavisi başlandı. Hastanın 1 hafta sonra kontrol odyogramında $27 \mathrm{~dB}$ düzelme saptanması üzerine hasta taburcu edildi. Taburculuğunu takip eden 3,8 ve 10 . aylarda yine sağ taraflı ani işitme kaybı ile başvuran hastaya her atakta hospitalizasyon ve intravenöz steroid tedavisi uygulandı. Hasta yaşadığı son işitme kaybı atağında, işitme kaybına kulakta dolgunluk ve baş dönmesinin de eklenmesi üzerine 15 gün sonra başvurdu. İlk 3 tedavisinde işitme kaybında düzelme saptanan hastanın son işitme kaybına yönelik tedavi sonrası odyogramında $65 \mathrm{~dB}$ sensörinöral işitme kaybının devam ettiği saptandi.

Rekürren ani işitme kaybının tanı ve tedavisine ilişkin çok az sayıda veri bulunmaktadır. Düşük frekansları tutan rekürren ani işitme kaybı, prognozu iyi olan hastalık grubundadır. Ancak ilerleyen dönemlerde rekürren hastalık yaşayan hastaların seyrinde sonradan kalıcı olabilen işitme kaybı ve Meniere hastalığına progresyon görülebilmektedir. Her hastada işitme kaybı derecesi ve seviyesi farklı olabileceğinden uzun dönem takip yapılması ve hastalık progresyonunun iyi dökümente edilmesi gerekmektedir.
\end{abstract}

Anahtar Kelimeler: İdiyopatik ani işitme kaybı, rekkürens, tedavi

\begin{abstract}
Sudden hearing loss is a common clinical condition which exact etiology is unknown and has no standard treatment. Whereas recurrent sudden hearing loss is extremely rare. Recurrent disease is associated with 2 clinical types including low and high frequencies. Idiopathic sudden hearing loss of low tone type is distinct from other sudden hearing losses of unknown etiology with preservation of high-tone hearing and without episodes of vegetative symptoms such as vertigo, nausea and vomiting. In this article a patient with sudden hearing loss of four times in an interval of several months was presented.

A 50-year-old men presented to our clinic with the complaints of tinnitus, buzzing, and hearing loss in the right ear for a few days. Otoscopic examination of the patient was normal and $55 \mathrm{~dB}$ of sensorineural hearing loss at low frequencies was present. Patient was hospitalized and intravenous steroid treatment was started. The patient's control audiogram showed $27 \mathrm{~dB}$ after 1 week and patient was discharged Three, 8 and 10 months following discharge, patient again admitted with rightsided sudden hearing loss and in each episode he was hospitalized and treated with intravenous steroids. The patient was admitted 15 days after the last episode with the inclusion of fullness in the ears and dizziness on his hearing loss. After the last treatment, it was found that audiogram showed $65 \mathrm{~dB}$ sensorineural hearing loss of the patient whose first three treatment showed improvement in hearing loss.

There are very few data related to the diagnosis and treatment of recurrent sudden hearing loss. Recurrent sudden hearing loss involving low frequencies is a group of diseases with a good prognosis. However, in the course of patients who experienced recurrent disease may progress to permanent hearing loss and Meniere's in later periods. The degree and the severity of sudden hearing loss of each patient may be different so long-term follow-up and well documentation of disease progression should be done.
\end{abstract}

Keywords: Idiopathic sudden hearing loss, recurrence, treatment
KÜ Tıp Fak Derg 2015; 17(1): 45-49

Geliş Tarihi / Received: 30.05 .2014

Kabul Tarihi / Accepted: 27.09.2014

\author{
Yazışma Adresi / Correspondence: Gökçe Şimşek \\ Kırıkkale Üniversitesi Tıp Fakültesi, KBB A.D., KIRIKKALE \\ E-posta: gokcesimsek@kku.edu.tr Tel: 03183573644
}




\section{GíRiş}

İşitmesi daha önce normal olan bir kişide 3 gün içerisinde gelişen ardışık 3 frekansta $30 \mathrm{~dB}$ ve daha üzeri düzeylerdeki sensörinöral işitme kayıpları, ani işitme kaybı (AİK) olarak tanımlanmıştır. AİK nadir bir otolojik acildir. Genel populasyonda insidansının 100.000'de 10,7 olduğunu bildirmektedir (1). Bu patolojinin sık tekrarladığı rekürren AİK ise oldukça nadir görülür ve insidansı bilinmemektedir. İşitme kaybına ek olarak vertigo, bulantı, kusma, tinnitus ve kulakta dolgunluk görülebilir (2). Sıklıkla unilateral olan AİK'nın etyolojisi tam olarak bilinmemektedir (3). Detaylı klinik, laboratuvar ve radyolojik görüntüleme yöntemlerine rağmen etyoloji ancak \%25 vakada öğrenilebilir (4). Hastalığın etiyopatogenezini aydınlatmaya yönelik bugüne kadar öne sürülen açıklamalar içinde viral enfeksiyonlar, vasküler oklüziv hastalık, alerjik reaksiyonlar, intralabirentin membran rüptürü, lokal antihistamin üretimi, perilenfatik fistula ve otoimmünite gelmektedir $(5,6)$. Rekürren AİK'nın klinik olarak düşük ve yüksek frekansları tutan tipleri bulunmaktadır (7). Düşük frekanslarda sensörinöral kayıpla karakterize idiyopatik AİK etyolojisi bilinmeyen diğer AİK'lardan, yüksek frekanslarda işitme eşiklerinin korunması ve vertigo, bulantı, kusma gibi vejetatif bulguların olmamasıyla ayrılır (8). Bu yazıda düşük frekanslarda sensörinöral işitme kaybı ile başlayan ancak daha sonraki rekürrenslerle kalıcı işitme kaybının eşlik ettiği Meniere hastalığına dönüşen nadir bir olgu sunumu literatür bilgileri eşliğinde sunulmuştur.

\section{OLGU}

Birkaç gündür devam eden sağ kulakta çınlama, uğultu ve işitme kaybı yakınması ile 50 yaşında erkek hasta kliniğimize başvurdu. Hastanın anamnezinde dengesizlik, baş dönmesi, kulakta dolgunluk gibi yakınmalar yoktu. negatifti. Geçirilmiş üst solunum yolu enfeksiyonu, kafa travması, ıkınma, ağır yük kaldırma gibi intraabdominal basınç artışı hikâyesi yoktu. Otoskopik muayenesinde bilateral aurikula ve dış kulak yolu doğaldı. Bilateral timpanik zar doğal olarak izlendi. Weber testi sola lateralize olan hastanın Rinne testi bilateral pozitifti. Göz muayenesinde nistagmus izlenmedi. Baş sallama testinde de nistagmus saptanmadi. Yapılan saf ses odyogramında sağ kulakta $55 \mathrm{~dB}$ düşük frekanslarda baskın olan sensörinöral işitme kaybı saptanması üzerine sağ ani işitme kaybı (AİK) tanısıyla hasta hospitalize edildi ve ilk gün 100mg metilprednizolon sonrasında $1 \mathrm{mg} / \mathrm{kg}$ intravenöz (IV) metilprednizolon tedavisi başlandı. Medikal tedavisinin 10. gününde yapılan kontrol odyogramında işitme kaybının 27dB'ye gerilediği izlenen hasta önerilerle taburcu edildi (Resim 1). Taburculuğunda 3 ay sonra 3 gündür devam eden sağ kulakta işitme kaybı yakınması ile tekrar başvurdu. Fizik muayenesi doğal olan hastanın çekilen temporal manyetik rezonans görüntülemesinde (MRG) pontoserebellar köşe ve iç kulak yapıları normal olarak izlendi. Saf ses odyogramında sağ kulakta $63 \mathrm{~dB}$ sensörünöral işitme kaybı saptandı. Laboratuvar tetkiklerinde hemogram, biyokimya ve tiroid fonksiyon testleri normaldi. Otoimmun etyoloji ayırıcı tanısıyla yapılan dâhiliye ve endokrin konsültasyonlarında patoloji saptanmayan ve c-ANCA, Anti-TPO (Antitiroid Peroksidaz Antikor) düzeyleri negatif olan hastaya yatırılarak IV steroid tedavisi başlandı. On gün sonra yapılan kontrol odyogramında işitme kaybının 28dB'e gerilediği izlendi (Resim 2). Hasta 5 ay sonra 2 gündür sağ kulağında işitme kaybı, çınlama şikâyeti ile başvurdu. Yapılan odyogramı sonucu sağ kulakta tekrarlayan ani işitme kaybı tanısıyla kliniğimize yatışı yapılan hastaya IV steroid tedavisi başlandı. Hastadan ikinci kez gönderilen otoimmün markerlar negatif olarak izlendi. Tedavi sonrası işitmesi düzelen hasta ayaktan kontrollere gelmek üzere taburcu edildi. Hasta 2 ay sonra yeniden sağ kulakta 15 gündür süren işitme kayb1, kulakta dolgunluk ve günde 1-2 kez dengesizlik şeklindeki baş dönmesi şikâyeti ile başvurdu. Bulantı, kusma yoktu. Göz muayenesinde nistagmus izlenmedi. Odyogramında sağ kulakta 65 dB SNIK saptandı (Resim 3). Yatışı yapılan ve streoid tedavisi başlanan 
hastanın işitmesinde düzelme olmadı. Dengesizlik şeklinde baş dönmesi yakınmasının azalmakla beraber devam ettiğini belirten hasta intratimpanik steroid tedavisi protokolüne dâhil edildi. İntratimpanik metilprednizolon $(62,5 \mathrm{mg} / 0.5 \mathrm{ml})$ tedavisi 10 gün boyunca 48 saatte $1 \times 1$ olarak uygulanan hastanın kontrol odyogramında anlamlı düzelme saptanmadı.

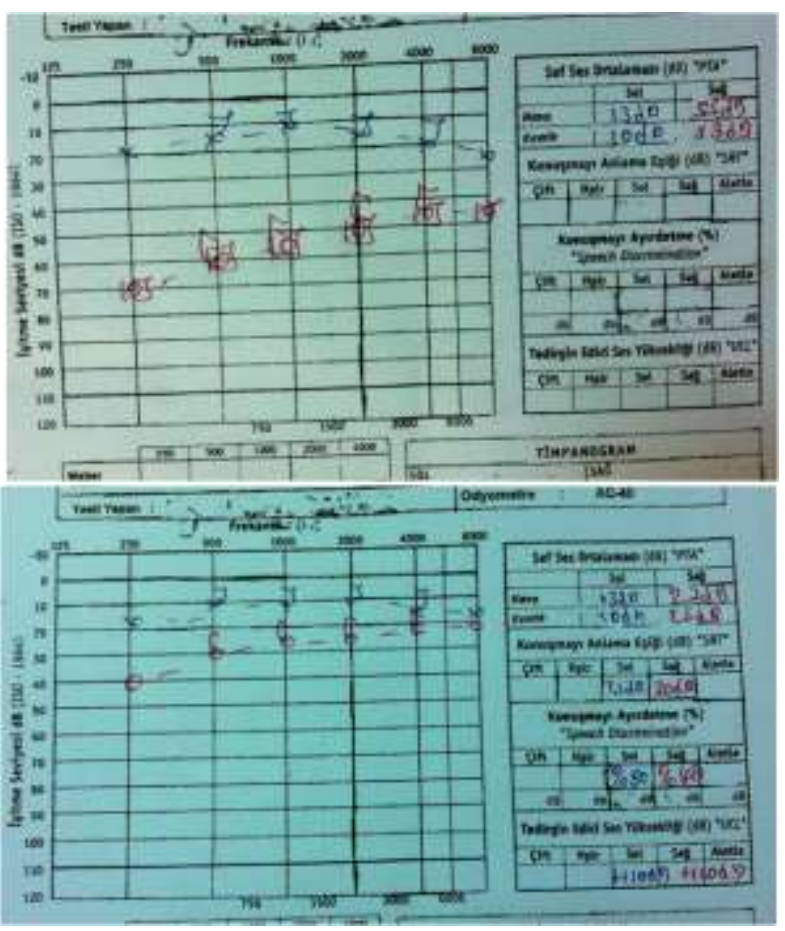

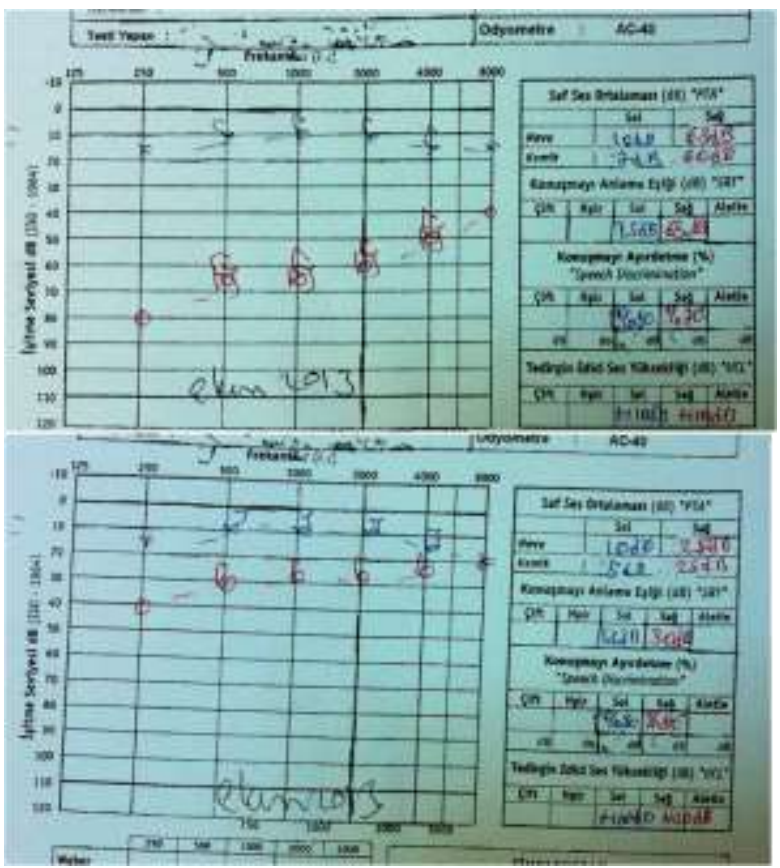

(Resim 2)

Resim 1: Hastanın ilk ani işitme kaybı anı ve tedavinin 5. günündeki odyogramları görülmektedir.

Resim 2: Hastanın ikinci atağında tedavi öncesi ve sonrası odyogramları görülmektedir.

$(\operatorname{Resim} 1)$

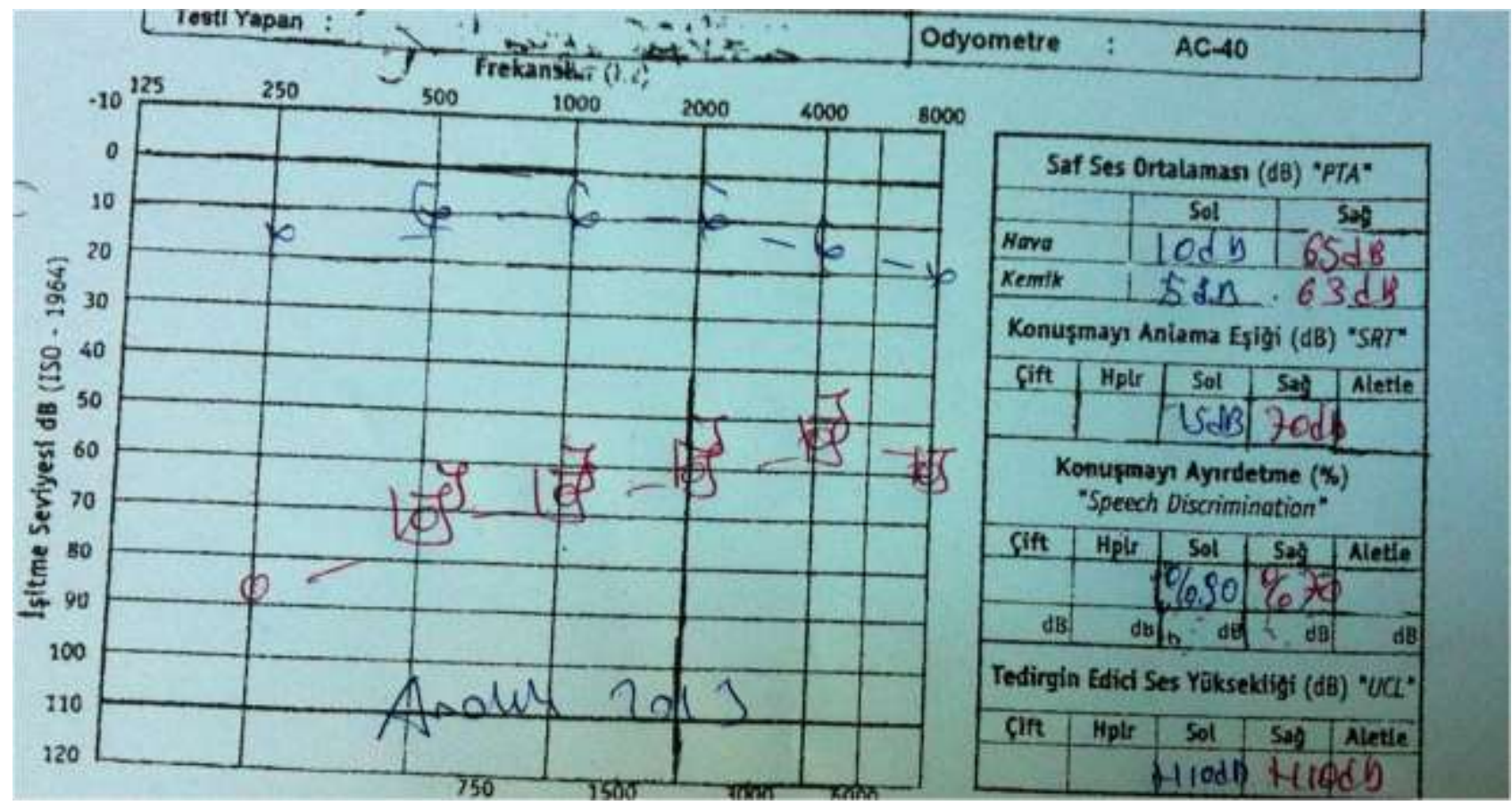

Resim 3: Hastanın dördüncü atağının tedaisinden sonra yapılan son odyogram tetkiki görülmektedir. 


\section{TARTIŞMA}

Rekürren AİK'nın tanı ve tedavisine ilişkin çok az sayıda veri bulunmaktadır. Rekürren AİK sıklıkla unilateraldir. Hastaların \%80'inde tinnitus, \%80'inde kulakta dolgunluk, \%30'unda da kulakta dolgunluk bulunmaktadır (9). Tedavisiz düzelme oranları \%32 ile 65 arasında değişmektedir. Ancak ilk 2 hafta içerisinde işitmesinde düzelme olmayan hastaların işitme kaybının kalıcı olabileceği bildirilmiştir (10). Hastalığın başlangıç semptomları arasında vertigo ve dengesizliğin varlığı ile saf ses odyogramında yüksek frekanslarda baskın olan bir işitme kaybının varlığı diğer kötü prognostik bulgulardır.

Düşük frekansları tutan, vertigonun eşlik etmediği, unilateral, idiyopatik sensörinöral ani işitme kaybı, prognozu iyi olan, alçak frekanslarda ani düşüş ile karakterize bir hastalık olarak ilk kez Japonyada tarif edilmiştir (11). Ancak literatürün kalanında konu ile ilgili oldukça sınırlı sayıda bilgi bulunmaktadır. Hastalardaki ana yakınma kulakta uğultu, çınlama, hiperakuzi ve işitme kaybıdır. Ancak ilerleyen dönemlerde rekürren AİK yaşayan hastaların seyrinde sonradan kalıcı olabilen işitme kaybı ve Meniere hastalığına progresyon görülebilmektedir. Fushiki ve ark.nın (11) yaptığı çalışmaya göre vertigonun eşlik etmediği idiyopatik sensörinöral ani işitme kaybının rekürrens oranı, hastalığın başlangıç anında yapılan Elektrokokleografi (ECoG) ve Elektronistagmografi (ENG) bulgularına göre değişkenlik gösterebilmektedir. Başlangıç testlerinde endolenfatik hidrops bulguları ile vestibüler bozuklukların varlığında rekürrens oranlarının \%80'lere çıktığını bildirmişlerdir. Pozitif bulguları olan bu hastaların \%15'inde Meniere hastalığına progresyon saptanmıştır.

Tedavide birçok seçenek denenmesine rağmen, steroidler en yaygın kullanılan ajanlardır. Gerek sistemik gerekse intratimpanik uygulamalar mevcuttur. Sistemik steroid tedavisinin literatürde ilk sonuçlarından birisi Wilson ve ark.'na aittir (12). Bu çalışmada orta ve ciddi AİK olan vakalarda steroid tedavisinin plaseboya göre daha iyi yanıt vermediği saptanmışlardır. Ancak orta-hafif işitme kayıplarında steroidin plaseboya göre iki kat fazla tedaviye yanıt sağladığını bildirmişlerdir. İntratimpanik tedavi ise steroidlerin sistemik yan etkilerinden kaçınmak için başlangıçta kurtarma tedavisi olarak denenmiş ve başarılı sonuçlar alınmıştır (14). Tedaviye cevabı etkileyen faktörlerin başında tedavinin zamanı gelmektedir. Bizim sunduğumuz olguda hasta ilk 3 atağında erken dönemde kliniğimize başvurmuştu ve tedaviye yanıt alınmıştı. Ancak hasta son geçirdiği ani işitme kaybı yakınmasından 15 gün sonra ve baş dönmesi şikâyeti de eklenerek başvurdu. Hastalığın seyri göz önüne alındığında son atağında Meniere hastalığı ön tanısı belirginleşmişti.

Sonuç olarak her hastada AİK derecesi ve seviyesi farklı olabilir. Son güncel literatüre göre tekrarlayan ani işitme kaybı ile başvuran hastalara elektrofizylojik testler yapılarak hastalığın ileri dönem seyri hakkında fikir sahibi olunabilir. $\mathrm{Bu}$ sebeple uzun dönem takip yapılması ve hastalık progresyonunun iyi dökümante edilmesi gerektiğini düşünmekteyiz.

\section{KAYNAKLAR}

1. Bliss MR, Jackler RK, Gurgel RK. Recurrent contralateral hearing loss after 2 craniotomies for vestibular schwannoma: etiologic implications. Otol Neurotol. 2013; 34(7): 1237-40.

2. Huang N, Li C. Recurrent sudden sensorineural hearing loss in a 58-year-old woman with severe dizziness: a case report. Acupunct Med. 2012; 30(1): 56-9.

3. Moon IS, Kim J, Lee SY, Choi HS, Lee WS. How long should the sudden hearing loss patients be followed after early steroid combination therapy? Eur Arch Otorhinolaryngol. 2009; 266: 1391-5.

4. Koç A, Sanisoğlu O. Sudden sensorineural hearing loss: Literature survey on recent studies. J Otolaryngol. 2003; 32 (5): 308-13. 
5. Park IS, Kim YB, Choi SH, Hong SM. Clinical analysis of recurrent sudden sensorineural hearing loss. ORL J Otorhinolaryngol Relat Spec. 2013;75(4): 245-9. doi: 0.1159/000353552.

6. Maiolo V, Savastio G, Modugno GC, Barozzi L. Relationship between multidetector CT imaging of the vestibular aqueduct and inner ear pathologies. Neuroradiol J. 2013; 26(6): 683-92.

7. Yamasoba T, Kikuchi S, Sugasawa M, Yagi M, Harada T. Acute low-tone sensorineural hearing loss without vertigo. Arch Otolaryngol Head Neck Surg. 1994; 120: 532-5.

8. Imamura S, Nozawa I, Imamura M, Murakami Y. Clinical observations on acute low-tone sensorineural hearing loss. Survey and analysis of 137 patients. Ann Otol Rhinol Laryngol. 1997; 106: $746-50$.

9. Sakata T, Kato T. Feeling of ear fullness in acute sensorineural hearing loss. Acta Otolaryngol. 2006; 126: 828-33.

10. Schreiber BE, Agrup C, Haskard DO, et al. Sudden sensorineural hearing loss. Lancet. 2010; 375: 1203-11.
11. Fushiki $\mathrm{H}$, Junicho $\mathrm{M}$, Aso $\mathrm{S}$, Watanabe $\mathrm{Y}$. Recurrence rate of idiopathic sudden low-tone sensorineural hearing loss without vertigo: a longterm follow-up study. Otol Neurotol. 2009; 30(3): 295-98.

12. Wei BP, Stathopoulos D, O'Leary S. Steroids for idiopathic sudden sensorineural hearing loss. Cochrane Database Syst Rev. 2013;7:CD003998. doi: 10.1002/14651858.CD003998.pub3.

13. Rauch SD1, Halpin CF, Antonelli PJ, Babu S, Carey JP, Gantz BJ, Goebel JA, Hammerschlag PE, Harris JP, Isaacson B, Lee D, Linstrom CJ, Parnes LS, Shi H, Slattery WH, Telian SA, Vrabec JT, Reda DJ. Oral vs intratympanic corticosteroid therapy for idiopathic sudden sensorineural hearing loss: A randomized trial. JAMA. 2011; 305(20): 2071-9.

14. Kiliç R, Safak MA, Oğuz H, Kargin S, Demirci M, Samim E, Ozlüoğlu LN. Intratympanic methylprednisolone for sudden sensorineural hearing loss. Otol Neurotol. 2007; 28(3): 312-6. 